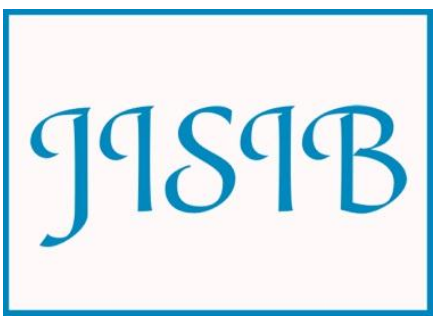

Available for free online at https://ojs.hh.se/

Journal of Intelligence Studies in Business 1 (2013) 59-68

\title{
The intelligence worker as a knowledge activist - an alternative view on intelligence by the use of Burke's pentad
}

\author{
Magnus Hoppe \\ Mälardalen University \\ School of Business, Society and Engineering (EST) \\ P.O. Box 883, 72123 Västerås, Sweden \\ magnus.hoppe@mdh.se
}

Received March 3 2013, accepted March 262013

\begin{abstract}
As society and business is becoming more complex, the creation and management of knowledge attracts more attention. For intelligence research it offers an alternative perspective on the art and science of intelligence that challenges a previous dominance of strategy and decision-making theories. The article is based on semi-structured interviews with intelligence personnel in four different multinational companies. Through the use of Burke's pentad this article gives an account of important challenges encountered by intelligence personnel in modern business organizations due to an increasing dependence on different knowledge processes. These challenges are summarized in four central tasks for knowledge activists; that is to initiate and focus knowledge creation, to reduce the time and cost needed for knowledge creation, to leverage knowledge creation initiatives throughout the corporation and to guide knowledge creation by the instigation of complementary reference points. By engaging in these types of activities intelligence workers are able to stage and influence different sorts of analytical conversations, where the insights from these conversations as reformed knowledge govern an evolving strategy in dispersed circumstances. Thus, intelligence workers fulfil their purpose, which in this perspective can be viewed as creating better business in whatever process they engage in.
\end{abstract}

KEYWORDS: Knowledge Activism, Knowledge Creation, Knowledge Management, Organizational learning, Organizational Change, Analytical Conversation, Complexity, Burke's Pentad, Competitive Intelligence, Organized Intelligence Work.

\section{Opinion Section}




\section{Introduction}

Technological and social changes make business environments less stable by the year, blurring our preconceived ideas of what constitutes an industry (Bettis and Hitt 1995). As early as 1965 Emery and Trist stated, "A main problem in the study of organizational change is that the environmental contexts in which organizations exist are themselves changing at an increasing rate, and towards increasing complexity" (ibid, 24). Since then the complexity of industries and their environments has come to interest an increasing number of academics (Andersson 1999), who address questions of how to manoeuvre fragmented companies in a complex society. As well as these visible signs of industrial renewal, there are also more subtle changes in organizational processes and the way organizations function. Many companies have turned to more knowledge intensive production, which has affected both core competencies and business design. Thus management of different knowledge processes has become particularly important.

This development challenges the idea of a central core controlling the organization like a machine. Instead ideas have been launched where control can be executed through influencing the mind-set of organizational members (Miller 1999). As Røvik (2000) puts it: "Leadership is increasingly a matter of coordination through mental manipulation as opposed to control of physical movements" (ibid, 279 , author's translation). Strategic coordination through formal decisions is thus not enough, challenging traditional ideas of the mission and purpose of competitive intelligence, even though these ideas are still central in contemporary descriptions of intelligence (e.g. McGonagle and Vella 2012).

Knowledge, and a not unproblematic relationship to knowledge management, has interested intelligence theorists since the 1990's at least (Tuomi 1999). More recently intelligence theory has also come to acknowledge complexity as an issue for intelligence professionals and theory. Gay (2012) points out that the new business circumstances that follow complexity ought to have effect on how to organize and implement intelligence. López et al. (2012) suggests that contextualisation of best practices in supply chain knowledge might counteract the strain that complexity puts on organizations. Whereas El Haddadi et al. (2011) argues that what used to be strategically planned now (due to increased complexity), to a greater extent, is limited to a strategic response, thus challenging ideas of proactivity. Instead, the strategic response must connect to widespread knowledge renewal activities that enable the company to innovate.
In line with this reasoning knowledge creation processes (Oubrich 2011) has come to interest intelligence researchers along with organizational learning (Steiner and Ploder 2011) as well as a still vital interest in knowledge management (López et al. 2012, Rothberg and Erickson 2012). Tuomi (1999) as well as Ghannay and Mamlouk (2012) argue that CI could be viewed as a subset of knowledge management, thus definitely changing the locus of intelligence from decision support to knowledge support. On the other hand there are arguments that even though the world changes, the need for good decision support is still a vital task for intelligence professionals (McGonagle and Vella 2012). Nan Bulger (2013), Executive Director of SCIP, emphasizes this view:

"Whether you are a practitioner, an academic, or a consultant focused on a myriad of business operational disciplines, the need for applied methods to garner and use intelligence in decision support remains."

Taking a decisional view, we can conclude that the increasing complexity is a real challenge for companies' decision makers, not only at the top level, but throughout entire organizations. An increasing number of strategic decisions are now made outside the control of top management, a phenomenon that was also noted by Emery and Trist in 1965 (cf. Eisenhardt 1989). For companies, the current situation makes new demands on internal services and functions that can help various decision makers and others to not only make informed decisions but also coordinate the decisions and actions taken with the rest of the organization; organizational entities that help leadership to coordinate organizational action. In knowledge based companies this demand expands the managerial dimension of a firm to other people and processes, so that the knowledge developed and applied is informed and coordinated. These types of assignments are now given to intelligence services and intelligence personnel inside business organizations; with their tradition of monitoring and analysing the environment they display the necessary competence. But it doesn't end there. As intelligence is getting more dispersed, intelligence personnel encounter new intelligence needs and dilemmas, thus creating new opportunities for novel research.

So far, the knowledge perspective has not been the pinnacle of intelligence research. Instead the field is dominated by research objectives aiming at delivering practical advice for the practitioner, cf. Rothberg and Erickson 2012, Solberg Søilen 2005). This is partly due to the strong influence from consultants in the formative phases of the intelligence field in the 1980's and onwards. The market for research favoured easily digested concept literature (Jackson 2001) with authors like Benjamin Gilad (1988, 1996, 2003, 2006) and Leonard Fuld (1995, 2006). 
The traditional writing was usually done in a managerial tradition (cf. Furusten 1999), where analytical methods for strategic decision making are given emphasis, carrying with them a traditional hierarchical view of how organizations function (cf. McGonagle and Vella 2012). This tradition has favoured a view on strategy as design where managers are in control of the organization (Mintzberg et al. 1998), overshadowing other views on strategy and organization. The dominance of this perspective is also due to a strong influence from military intelligence traditions (e.g. Meyer 1987, Wilensky 1967). What's also noticeable is that the emergence of the intelligence field coincided with theoretical ideas of strategy planning, especially made popular by Michael Porter in the 1980s. Porters (1980, 1985) Value Chain analysis respectively Five Forces model still attract attention today as it indirectly calls for internal and external intelligence. In this theoretical tradition analysis of the business environment is judged to be the core competence of management as it enables managers to create strategy and design the organization by informed decisions about a specific market position to aim for and defend. Accordingly managers also need analysis support, upholding a perspective that emphasises the intelligence practitioners' analytical skills and downplaying other aspects of the work.

The increasing complexity in both business design and society has thus far not led to a major reformation of this dominant view of intelligence. As stated, there are emergent research initiatives that could introduced alternative descriptions of intelligence, uncovering important dimensions and aspects that will help form an intelligence science. Especially knowledge management and knowledge creation are deemed promising for this advancement (cf. Rothberg and Erickson 2012). In line with this reasoning we provide here an exploration of questions and problems that could be fruitful areas for new research on intelligence, especially considering knowledge aspects. This leads me to phrase the purpose of this article as follows:

to give an account of important challenges encountered by intelligence personnel in modern business organizations due to an increasing dependence on different knowledge processes.

\section{Method and materials}

The empirical material consists of a total of 18 semi-structured and transcribed interviews, mainly with intelligence professionals (but also in one case [Case 1] people in the surrounding organization) spanning four different large multinational companies (all referred to by pseudonyms $\mathrm{C} 1-\mathrm{C} 4$ in this article). All companies studied were very well experienced in the organization and use of intelligence, and had a back log of organized intelligence work since the 1990s or even longer.
C1 (Case 1) is a global pharmaceutical company, and interviews were conducted at their country headquarters. $C 2$ (Case 2) is a global electronic company, and interviews were also conducted at their country headquarters. $C 3$ (Case 3 ) is a global packaging company, and interviews were conducted at the country headquarters. C4 (Case 4) is a subsidiary of a European chemical company with a global market, interviews were conducted at the headquarters of the country subsidiary. Complimentary research material was gathered e.g. through emails and company websites, as well as through discussions with various intelligence professionals at conferences and other gatherings.

The analytical constructs presented in this article are developed inductively, and made visible through the transcription and coding process of the material as well as the intellectual process of making sense of the material at hand. Burke's pentad (Burke and Gusfield 1989) was used as an organizing tool for the sense-making part, where the pentad was adapted to suit the specific circumstances of this paper. The drama-metaphor emanating from Burke is used to make some of the points under discussion stand out.

The empirical material is presented in aggregated form. The paper begins with an explorative section, presenting the initial findings. These findings are used in the later section to build a discussion around the challenges now facing intelligence personnel, thus addressing the stated purpose of this article.

\section{Results}

From the data at hand, several aspects of intelligence emerge as interesting candidates to meet the stated purpose. In the sections below I will elaborate on five themes based on Burke's pentad, where purpose, scene, agent, and agency are presented under Results but the actual act is the theme for the discussion. The paper ends by raising questions about the type of play we are witnessing and the challenges this creates for the actors, which in this case equals intelligence personnel.

The themes presented are of course intertwined, and aspects of each theme can be found under different headings.

\subsection{Purpose: Intelligence in order to create bet- ter business}

The interviewees described their work as mainly consisting of gathering, analyzing and disseminating information in order to support decision-making in general. The interviewees still used the term decision support while describing their work, even though the decisions to be made were not that well defined or were not clear-cut decisions. If we limited ourselves to the self-descriptions of the interviewees we would most likely come pretty close to 
traditional ideas of strategy making and ideals of informed decisions.

Even though this self-description of intelligence and decision support was more or less generic, there were other aspects of their work that transcended this quite limited sphere of activity. The missions guiding the work were not focused on decisions. Instead they were about supporting a special part of the company or a specific process. An analyst at $\mathrm{C} 2$ pointed out that their mission functioned as a good guideline for what to do and what to strive for; phrasing the mission as follows "our mission is to support the sales force with competitive knowledge and arguments in order to win the deal, and do profitable business."

With missions like the one cited intelligence practitioners were encouraged to try different methods and techniques to expand their scope of work, e.g. to create and stage war stories that forced those involved to reflect and act in simulated business situations (cf. Oubrich 2011). Except for financial and moral considerations, the interviewees did not mention any real limitations to the scope of their work. In this respect the decision-making selfreference did not constitute an obstacle to expanding their field of practice. Decision support therefore appears to be an important idea for defining the intelligence identity, but the missions given guide the practice, and these missions are, to put it simply, about creating better business.

\subsection{Scene: Dispersed intelligence}

Intelligence had more than one place (scene) in each of the researched organizations. It was dispersed around the organizations and could be found e.g. in the central core, subsidiaries and connected to designated project teams. Intelligence units mostly worked independently of one another, serving their specific part of the organization. The $\mathrm{C} 1$ unit concentrated on promoting marketing issues and filling information and analytical gaps in different project teams. The $\mathrm{C} 2$ unit concentrated on supporting key account managers who would give $\mathrm{C} 2$ the upper hand in future deals. The C3 unit concentrated on identifying and making use of new ideas and technology in support of the R\&D part of the organization. The $\mathrm{C} 4$ unit, located in a subsidiary, concentrated on handling strategic issues arising from all over the organization in an effort to help almost anyone who was in need. The context and the mission descriptions differed, but regardless of the particular context (scene) all interviewees classified themselves as intelligence practitioners.

There was collaboration between intelligence units at each investigated company, e.g. for buying information or skill training, but the collaboration was a result of common interests more than a coor- dination effort designed by a central intelligence manager. Whereas most collaboration was within the boundaries of each organization, the unit at $\mathrm{C} 4$ collaborated with units at other subsidiaries and at headquarters (cf. Steiner and Ploder 2011).

Even though the intelligence workers interviewed worked in dispersed circumstances, their stories contained passages that made it clear that the top levels of the investigated organizations had their own designated intelligence services. However, these intelligence units assigned to top management worked independently from the others, answering to the local needs expressed and experienced in the interfaces developed between supporters and those supported. One exception to this was occasional strategic overviews and projects where crossfunctional teams of intelligence personnel were formed, working together towards common goals for a limited time. In these specific situations hierarchical order emerged as important in defining the work to be done. This however was the exception to the rule. Thus, intelligence in this study appears to be locally organized, and close to those designated to benefit from the service. Intelligence also plays out more as a loosely coupled network of distinct units and less as a hierarchically organized and coherent support structure for a central core.

Rothberg and Erickson (2012) state that this type of independent and distributed intelligence is a sign of a more mature intelligence organization that over the years has been able to develop more effective processes. It is also a type of intelligence more common in high-value knowledge industries, which in the citation under the previous heading also is visible in the informant's choice of words. He does not simply use "competitive intelligence" but instead "competitive knowledge and arguments", referring to something else than just decision support. Together with complementary descriptions of how intelligence is used to enhance a specific knowledge need, one is inclined to say that when the intelligence organization matures, it is moving away from the tight leash of decision support defined by the hierarchical system, towards a position where intelligence functions as knowledge support is defined by the parties involved.

\subsection{Agent: Serving the willing}

Traditionally, intelligence is described as a function that works on the demands from the decisionmakers they are to serve. There is a clear distinction between those who experience and express an informational need and those who act to satisfy this need. In the common visualization of the intelligence process below (Figure 1) the planning task is the prerogative of decision makers and the three other tasks are the responsibility of the intelligence unit (cf. McGonagle and Vella 2012). 


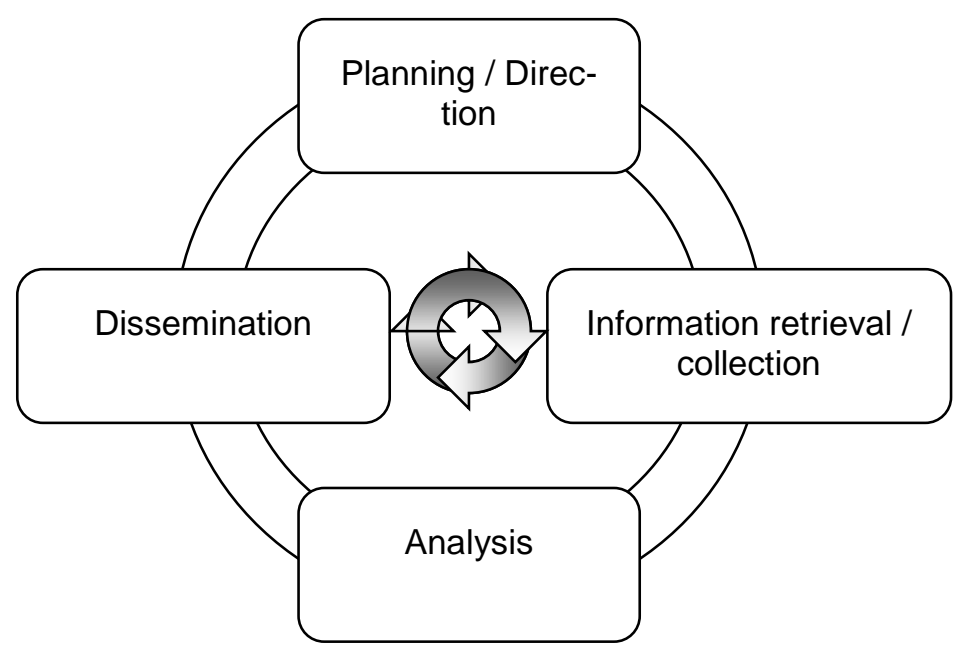

Figure 1: The intelligence cycle (traditional)

Conceptually the model is quite correct. Unfortunately it describes the intelligence process on a simplified organizational level and not on a complex individual level. With the model the organization appears to be a coherent whole with a common mind, where the brain controls the limbs. This description has its roots in ideas emanating from taylorism and fayolism, with clear functional divisions between employees, which in a complex knowledge economy stand out as quite obsolete. Today it's more common to view organization as a network of loose connections between individuals, where the individuals are limited to a most personal quest of making sense of the world no matter what official function they uphold (Hamrefors 1999).

Turning to the data at hand, and as mentioned earlier, there was no clear distinction between those who did the planning and those who did the fieldwork. Instead the division appeared to be nonexistent as both intelligence personnel and intelligence users cooperated to complete the tasks they identified. Thus, we have the combining of efforts of understanding and refining the question and making sense of the world.

Occasionally there were clear-cut assignments, but most of the time the experienced and expressed need was something that evolved through discussion between the parties involved (cf. Treverton 2004). I would like to stress here that the active party was usually not the information user/decision maker, but rather the intelligence worker. Interviewees frequently revisited the fact that they had to market their services internally to their intended users. It was also common that intelligence personnel went on road trips to different countries, invited themselves to meetings, and laid out plans how to reach certain people internally who they felt had something to gain through their work (but also in some cases were believed to be in possession of valuable information/knowledge that could be put to use elsewhere in the organization).

In conclusion, we find that intelligence work is not so much passively awaiting requests from designated end-users than actively influencing parties in the organization that will help the intelligence workers reach important goals targeted by them in their quest of fulfilling their mission of creating better business. Therefore intelligence workers are limited to serve those who are willing. The role of the agent can also be said to shift depending on purpose, scene and how the agency has developed, but nonthe less the interviewees classified themselves as intelligence practitioners.

\subsection{Agency: Analytical conversations}

Describing their work, the interviewees favoured stories involving actions like scouting, informing, providing a second opinion, and working as internal consultants. However none of these descriptions stands out as well as analyzing, a verb used frequently throughout the interviews.

Scrutinizing the data, one can also conclude that most of the time the interviewees' work (and thus analysis) was focused on issues other than those directly connected to decision-making. Instead, much of their work and the artefacts produced were for wider purposes. Routine tasks included organizing and participating in discussions, updating standard analysis of particular market sectors, checking and making sense of rumours, and keeping files and profiles on competitors.

So, if decision support is not enough to define intelligence and many other activities are being performed in order to fulfil the overarching goal of creating better business, are there other and possibly better ways to understand intelligence? I believe there are. Here I suggest that instead of paying too much attention to the intelligence workers' self- 
descriptions and the specific artefacts being produced, we should consider both what happens around these artefacts and around the practitioners themselves. Taking this leap of mind brings us to a another perspective that focuses on the interaction among organizational members, where different intelligence artefacts and intelligence initiatives can be viewed as created reference points for continuous reflection and action in order to build better business (cf. Argyris and Schön 1995). By continuous interaction as well as the creation and maintenance of intelligence artefacts intelligence personnel influence what's being discussed inside the organization. Henceforth they are turning organizational attention towards certain aspects and away from others, and when organizational members' ideas and experiences are affected we can also say that their knowledge has been manipulated.

As noted above intelligence literature favours a description of intelligence as a service working on the command of decision makers, preferably defined through the use of models like the one shown in Figure 1. In this model analysis is the third step in the process of developing raw information into intelligence (principally as intelligence artefacts). When the analytical step is completed the constructed intelligence is ready to be disseminated to the decision maker, hopefully fulfilling the information need that triggered the intelligence process in the first place.

Turning to the cases, this description is to some extent true, where e.g. at $\mathrm{C} 1$ different people and projects turned to their designated intelligence service with requests for intelligence (especially frequent in areas where they lacked necessary expertise or when they experienced time restraints). In these cases the intelligence personnel were also adding value by giving voice to facts and perspectives not present in the requesters frame of reference. Nevertheless, even in these specific cases most of the intelligence workers were active in both defining the request as such and in building a common idea of how to perform the quest, depending on the insights that were gained in the process. Those who expressed this intelligence need were mostly also involved in fulfilling it throughout the process. There was not just initiation and delivery; there was continuous dialogue throughout a sensemaking process where both parties (and others) performed tasks that helped solve the identified intelligence / knowledge need (cf. Treverton 2004).

A technical scout at $\mathrm{C} 3$ expressed that an important part of his job was to stage interesting discussions and processes so that a rough idea could develop into something useful for the company. Different people from both inside and outside the company took part in these analytical discussions as the idea evolved, formalizing itself into an action plan with the objective of making the company more viable, e.g. through a better process, product or service. The responsibility and organizational home of the idea (and thus the discussion) also changed during the process through mutual adaptation. The technical scout's actions were congruent with his overall organizational mission of creating better business, and were not limited to a clearly defined place in an organizational chart or a sequence in a model for intelligence creation.

Another example of how analytical discussions emerged as the core process for intelligence workers was given by an analyst at $\mathrm{C} 2$. He expressed that different analytical models of course came in handy in order to create all sorts of templates and texts, but as he pointed out, this was not the end goal. Instead he emphasized that the most important outcome of using a model was the discussion that it triggered.

In these examples we see that an organization is in fact a place for organizing, and that organizing is an on-going matter between organizational members, especially synchronized through speech and other communicative tools. Formalities like organizational charts, work descriptions and even standard intelligence artefacts are just tools that help us keep some sort of order in the organization (or at least give the impression that order exists, cf. Brunsson 2002, 2006, Røvik 2000). However all these things, though useful for understanding an organization, do not reveal the true organization. Instead, the organization is always an act of becoming, where those with the position and ability to influence play an important role.

The intelligence services, as described in my study, can in this perspective be regarded as specific organizational entities with a mission to influence those knowledge structures that guide behavior in designated business processes. This is quite the opposite to a more traditional view on intelligence services as passive producers of intelligence artifacts. The problem with the latter position is that it limits the role of the intelligence worker to that of a bystander, with no interest of his or her own, not participating in the organizational power games, and working on the whims of others. As my study show, this description unnecessarily limits our understanding of how intelligence affects organizational behavior. The knowledge perspective is in this case better as it opens up for complementary views and ideas of how intelligence can support different business processes. This is to a large extent done by facilitating and even staging analytical discussions that intelligence personnel think will be fruitful for themselves (fulfilling their mission) and other participants. The use of analysis thus resembles the use of scenarios, which Kees van der Heijden (2005) describes as the art of strategic conversation. The scenarios and the analytical artifact fulfill the same purpose as they force us to 
communicate and build common ideas of what's important inside and outside the company. Intelligence thus complements long-term strategic conversation fueled by scenarios with a more shortterm analytical conversation fueled by the supply of complementary reference points. By doing this, intelligence also helps the organization to create new knowledge in order to fulfill the mission of the company.
So what is the act? What do we see in the scene where the intelligence workers operate? I see a different kind of play to that most authors in the field traditionally chose to present. To begin the discussion I will present four different aspects (Table 1) of how intelligence work appears in my study in relation to how it has traditionally been described. Building on the ideas of Burke, I have also constructed a drama metaphor to make each aspect clearer.

\section{Discussion: Act!}

\section{Change in appearance as descriptive text \\ The intelligence mission has changed from being a passive information service working on the command of high-ranking decision makers to an active internal agent for better business.}

Hierarchical position does not determine where intelligence is to be found. Instead the deployment of intelligence comes from dispersed needs displayed in each unique subpart of an organization.

Intelligence work moves away from the creation of intelligence artefacts to the creation of analytical conversations and the advocacy of distinct reference points in these conversations.

Intelligence is personalized in two dimensions, firstly the analyst comes forth as an individual agent with a personal network, and secondly the intelligence produced is adapted to the individuals and the specific situation at hand.

\section{Change in appearance as drama-metaphor}

Intelligence workers are not reading from a script, they are improvising around a specific topic.

Intelligence workers have now left the Dramatic institute in favour of being a travelling theatrical company.

The distinction between actors and audience dissolves to the extent that together they define the play as they speak.

At least compared to older plays involving the whole ensemble, intelligence is becoming more personal.

Table 1: Summary of how intelligence appears in my study in relation to the traditional view, presented both as a descriptive text and as a drama-metaphor.

With reference to the results presented above and these four points one can conclude that intelligence of today deals less with formal decisions and more with both formal and informal analytical conversations. This change of focus also moves the subject of intelligence away from decision making towards the field of knowledge creation (cf. Oubrich 2011). It is hard to distinguish whether this has to do with real changes in the practice of intelligence or if these changes can be traced back to a more paradigmatic change in society. Perhaps we have just learned to both see and speak about aspects of intelligence that were already present earlier when we didn't have the perspective and words needed to describe them. One could also object that the data used is skewed and/or that the intelligence presented above is culturally dependent where Scandinavian intelligence practice always has been more democratically organized and less formal.
Nevertheless, we can at least say that the practice of intelligence described above fits well into the knowledge discourse that has developed alongside changes in industrial logics and increasing complexity in recent decades. It also seems that intelligence has a role to play in today's knowledge based industries, supporting more balanced and profitable knowledge constructs, thereby contributing to developing more viable businesses. Even if it is just a Scandinavian model for intelligence, it is still something to reflect on when considering how we should organize intelligence in a more knowledge intense world with blurred industrial borders.

Working so closely with information and analysis one might have suspected that intelligence practitioners would also use the term knowledge in defining the purpose of their work. The word knowledge was employed on and off (cf. the citation above), 
but in an everyday fashion where knowledge appears synonymous with aggregated or analysed information. The intelligence workers did not call their work knowledge management (cf. Pirttimäki 2007), market analysis or anything along those lines. Instead they used the English term intelligence most of the time (even though the interviews where held in another tongue), but that should not hinder us from seeing them as highly active in influencing the knowledge used inside the organization, or even the knowledge defining the organization as such.

Changing the locus of the intelligence subject from decision support to knowledge support and knowledge creation will also open the field for other intelligence descriptions, where in the examples given we can interpret the intelligence worker as a knowledge activist, here described by von Krogh et al. (1997, 475):

"The knowledge activist is someone, some group or department that takes on particular responsibility for energizing and coordinating knowledge creation efforts throughout the corporation. We believe that such activism will have three purposes, the first of which is to initiate and focus knowledge creation, the second to reduce the time and cost needed for knowledge creation, and the third to leverage knowledge creation initiatives throughout the corporation. Knowledge activism can reside in a particular department or with a particular person, but it can also be situated in already existing departments and functions, or it can be taken up as a special assignment by individuals or departments."

Important in this quote is the central concept of knowledge creation, which indirectly implies a development of, or change in knowledge as a result of knowledge activism. What von Krogh et al. misses out on in the citation above is that knowledge creation also need to be guided in a certain direction and enhanced through the instigation of complementary reference points. Intelligence services can do just that, which also makes intelligence personnel most suitable for taking on a role of knowledge activists. Building on this it is even more obvious that intelligence workers do participate in the on-going power struggle inside the organization that define the ideas that guide organizational actions. Another way of phrasing this, with reference to Røvik (2000, 279), is to emphasise that intelligence is about mental manipulation and thus constitutes a vital leadership tool for those in a position to influence the missions given.

Perhaps, as Nonaka points out (e.g. Nonaka and Takeuchi 1995, Nonaka et al. 2000, Nonaka et al. 2006), western thinking has paid too much emphasis on knowledge as a physical product, an intelli- gence artifact (as apparent in traditional intelligence literature), and has neglected the immaterial aspects of knowledge as personal and collective insights. This could at least explain the dominant view on intelligence as decision support still present in today's discussions and literature.

\section{Conclusion}

This article shows that there are complementary ways of understanding the role of intelligence in organizations. Intelligence workers are already engaged in the creation and management of strategic knowledge, which is done in parallel to supporting informed and outspoken decisions. This is mainly done by initiating and upholding analytical conversations in dispersed circumstances, answering to local needs for better knowledge. By doing this they fulfill their purpose of creating better business, where the end result appears more prominent than the analytical artifacts produced in pursuit of this goal. With this description, intelligence workers stand out as designated knowledge activists, or if you like knowledge intelligence activist, with four main responsibilities.

* To initiate and focus on knowledge creation,

* To reduce the time and cost needed for knowledge creation,

* To leverage knowledge creation initiatives throughout the corporation, and

* To guide knowledge creation by the instigation of complementary reference points.

If we chose to take this leap of mind, I think that these four responsibilities are the most important challenges for today's intelligence personnel who seek a central role in those knowledge intense firms among those who aim to prevail in an increasingly complex world.

\section{References}

Andersson, Philip. 1999. Complexity Theory and Organization Science. Organization Science, Vol. 10, No. 3, pp. 216-232.

Argyris, Chris, and Schön, Donald A. 1995. Organizational learning II: theory, method and practice. Reading, Mass.: Addison-Wesley.

Bettis, Richard A., and Hitt, Michael A. 1995. The new competitive landscape. Strategic Management Journal, Vol. 16, Iss. S1, pp. 7-19.

Brunsson, Nils. 2002. The organization of hypocrisy : talk, decisions and actions in organizations. Malmö: Liber ekonomi.

Brunsson, Nils. 2006. Mechanisms of hope: maintaining the dream of the rational organization. Malmö: Liber. 
Bulger, Nan. 2013. The world has changed and so must we. Scip.Insight. Vol. 5, Iss. 3. $<$ http://scip.cms-

plus.com/files/publications/scipinsight/SCIP13 V5February FR2.htm> (accessible February 26, 2013)

Burke, Kenneth, and Gusfield, Joseph R. 1989. On symbols and society. Chicago: University of Chicago Press.

Eisenhardt, Kathleen M. 1989. Making Fast Strategic Decisions in High-Velocity Environments. The Academy of Management Journal, Vol. 32, No. 3, pp. 543-576.

El Haddadi, Anass, Dousset, Bernard and Berrada, Ilham. 2011. Establishment and application of Competitive Intelligence System in Mobile Devices. Journal of Intelligence Studies in Business, Vol. 1, No. 1, pp. 87-96.

Fuld, Leonard M. 1995. The New Competitor Intelligence : The Complete Resource for Finding, Analyzing, and Using Information About Your Competitors. New York: John Wiley and Sons.

Fuld, Leonard M. 2006. The secret language of Competitive Intelligence : How to see through and stay ahead of Business Disruptions, Distortions, Rumors, and Smoke Screens. New York: Crown Business.

Furusten, Staffan. 1999. Popular management books : how they are made and what they mean for organisations. London: Routledge.

Gay, Brigitte. 2012. Competitive Intelligence and Complex Systems. Journal of Intelligence Studies in Business, Vol. 2, No. 2, pp. 5-14.

Ghannay, Jihane Chebbi, and Mamlouk, Zeineb Ben Ammar. 2012. Synergy Between Competitive Intelligence and Knowledge Management a key for Competitive Advantage. Journal of Intelligence Studies in Business, Vol. 2, No. 2, pp. 23-34.

Gilad, Benjamin. 1988. The business intelligence system : a new tool for competitive advantage. New York. N.Y.: American Management Assoc.

Gilad, Benjamin. 1996. Business Blindspots : replacing myths, beliefs and assumptions with market realities. Calne: Infonortics.

Gilad, Benjamin. 2003. Early Warning : Using Competitive Intelligence to Anticipate Market Shifts, Control Risk, and Create Powerful Strategies. Saranac Lake. N.Y.: AMACOM.

Gilad, Benjamin. 2006. Neither a War nor a Game. Competitive Intelligence Magazine, Vol. 9, No. 6, pp. 6-11.
Hamrefors, Sven. 1999. Spontaneous environmental scanning : putting "putting into perspective" into perspective. Stockholm: Economic Research Institute.

Jackson, Brad. 2001. Management Gurus and Management Fashions. London: Routledge.

López, Gabriela, Eldridge, Steve, Montejano, Salomón, and Silva, Patricia. 2012. Competiveness from Contextualisation of Supply Chain Knowledge. Journal of Intelligence Studies in Business, Vol. 2, No. 2, pp. 42-50.

McGonagle, John J. and Vella, Carolyn M. 2012. Proactive Intelligence : The Successful Executive's Guide to Intelligence [Electronic resource]. London: Springer London

Meyer, Herbert E. 1987. Real World Intelligence : Organized Information for Executives. New York: Grove Weidenfeld.

Miller, Katherine. 1999. Organizational Communication: Approaches and Processes, $2^{\text {nd }}$ Edition. Belmont, CA.: Wadsworth.

Mintzberg, Henry, Ahlstrand, Bruce, and Lampel, Joseph. 1998. Strategy safari. London: Financial Times / Prentice Hall.

Nonaka, Ikujiro, von Krogh, Georg, and Völpel, Sven. 2006. Organizational Knowledge Creation Theory : Evolutionary Paths and Future Advances. Organization Studies, Vol. 27, No. 8, pp. 1179-1208.

Nonaka, Ikujiro, and Takeuchi, Hirotaka. 1995. The knowledge-creating company : how Japanese companies create the dynamics of innovation. New York, N.Y.: Oxford University Press.

Nonaka, Ikujiro, Toyama, Ryoko, and Konno, Noboru. 2000. SECI, Ba and Leadership : A Unified Model of Dynamic Knowledge Creation. Long Range Planning, Vol. 33, No. 1, pp. 5-34. [edited version in: Little, Stephen, and Ray, Tim. (Eds.). 2005. Managing Knowledge : An Essential Reader, $2^{\text {nd }}$ Edition (pp. 23-50). The Open University: Sage.]

Oubrich, Mourad. 2011. Competitive Intelligence and Knowledge Creation - Outward insights from an empirical survey. Journal of Intelligence Studies in Business, Vol. 1, No. 1, pp. 97106.

Pirttimäki, Virpi. 2007. Comparative Study and Analysis of the Intelligence Activities of Large Finnish Companies. Journal of Competitive Intelligence and Management, Vol. 4, No. 1, pp. 147-170.

Porter, Michael E. 1980. Competitive strategy : techniques for analyzing industries and competitors. New York: The Free Press. 
Porter, Michael E. 1985. Competitive Advantage : Creating and sustaining superior performance. New York: The Free Press.

Rothberg G. Scott, and Erickson, Helen N. 2012. Benchmarking Competitive Intelligence Activity. Journal of Intelligence Studies in Business, Vol 2, No 3, pp 5-11.

Røvik, Kjell Arne. 2000. Moderna organisationer : Trender inom organisationstänkandet vid millennieskiftet. Malmö: Liber.

Solberg Søilen, Klaus. 2005. Introduction to Private and Public Intelligence: The Swedish School of Competitive Intelligence. Lund: Studentlitteratur.

Steiner Michael, and Ploder Michael. 2011. Knowledge and social networks : New dimensions of economic interaction between firms.
Journal of Intelligence Studies in Business, Vol. 1, No. 1, pp. 49-60.

Treverton, Gregory F. 2004. Reshaping National Intelligence for an Age of Information. Cambridge: Cambridge University Press.

Tzu, Zi. 1995. Om krigets konst. 383 maximer om att segra och besegra. Stockholm: Nerenius and Santérus Förlag.

Wilensky, Harold L. 1967. Organizational Intelligence. Knowledge and Policy in Government and Industry. New York/London: Basic Books.

von Krogh, Georg, Nonaka, Ikujiro, and Ichijo, Kazuo. 1997. Develop Knowledge Activists! European Management Journal, Vol. 15, No. 5, pp. 475-483. 